\title{
Indications, Efficacy, and Safety of Intranasal Corticosteriods in Rhinosinusitis
}

\author{
Paul C. Potter, MD, FCP(SA), FAAAAI, FACAAI, ${ }^{1}$ and Ruby Pawankar MD, PhD ${ }^{2}$
}

\begin{abstract}
Rhinosinusitis is a significant health problem, causing significant morbidity and resulting in considerable financial cost. Some patients suffer persistent or recurrent symptoms despite receiving optimal medical and surgical treatment. Rhinosinusitis can be acute or chronic, acute often due to viral or bacterial infections and chronic which is classified into chronic with nasal polyposids or chronic rhinosinusitis without nasal polyposis. The disease affects the quality of life significantly and presents a significant burden on health costs globally. The anatomical linkage of the nose with the paranasal sinuses facilitates a common pathology in both organs. Chronic rhinosinusitis (CRS) has heterogeneous origins, including viruses, bacteria, fungal infections, anatomical abnormalities, polyposis, and aspirin sensitivity. Other conditions such as human immunodeficiency virus acquired immunodeficiency and cystic fibrosis may also be predisposing factors. Nasal polyposis is often associated with increased numbers of Th2 lymphocytes, fibroblasts, goblet cells, mast cells, and eosinophils, with upregulation of IL-13 and the release of specific IgE to staphylococcal enterotoxins. There is recent evidence that antibiotic treatment may not be as effective as higher doses of intranasal steroids in acute uncomplicated rhinosinusitis, especially in those with allergic disease. The broad inflammatory basis of the pathology of CRS also reveals a cellular infiltrate theoretically suppressed by intranasal corticosteroids. This has been confirmed in recent clinical studies of CRS with or without polyps. A treatment approach based on such studies reported in the European Position Paper on Rhinosinusitis guidelines and a guideline summary are presented. The current review represents the proceedings of a session ( 3 talks) by the authors at the first Middle East-Asia Allergy, Asthma, Immunology Congress in 2009.
\end{abstract}

Key Words: rhinosinusitis, nasal polyposis, corticosteroids

(WAO Journal 2012; 5:S14-S17)

$\mathrm{R}$ hinosinusitis is defined as inflammation of the nose and paranasal sinuses characterized by 2 or more symptoms, one of which should be either nasal blockage/congestion or

From the ${ }^{1}$ Allergy Diagnostic and Clinical Research Unit, University of Cape Town, South Africa; and ${ }^{2}$ Allergy and Rhinology, Nippon Medical School, Tokyo, Japan.

The authors have no funding or conflicts of interest to disclose.

Correspondence to: Ruby Pawankar, MD, PhD, Nippon Medical School, 1-1-5, Sendagi, Bunkyo-ku, Tokyo, Japan 113. E-mail: pawankar.ruby@gmail. com. Tel/Fax:81-3-5802-8177.

Copyright (c) 2012 by World Allergy Organization nasal discharge (anterior/posterior nasal drip) and may be associated with facial pain or pressure and/or a reduction in smell. ${ }^{1}$ In addition, there may be either endoscopic signs of polyps and/or mucopurulent discharge primarily from the middle meatus and/or edema or mucosal obstruction primarily in the middle meatus and/or computed tomography changes showing mucosal thickening within the osteomeatal complex and/or the sinuses.

Rhinitis usually coexists with sinusitis, and the most effective diagnostic and management strategies address both conditions. The disease severity is best assessed using a 10 -point scoring system or visual analogue scale from 0 to 10 and is in this way classified as mild (0-3), moderate (4-7), and severe (0-10), with a visual analogue scale of $>5$ shown to adversely affect a patient's quality of life. ${ }^{2,3}$

The disease may also be divided into acute rhinosinusitis (ARS) or chronic rhinosinusitis (CRS). ARS may also occur recurrently, with the patient not experiencing symptoms of CRS between the acute episodes. In ARS, patients have symptoms lasting less than 12 weeks, and the disease remits completely. ARS may be due to common cold (usually identified when there is an increase in nasal symptoms after 5 $\mathrm{d}$ or persistent symptoms after $10 \mathrm{~d}$ but with less than 12 -wk duration). CRS (with or without nasal polyps) is diagnosed when the patients have symptoms of rhinosinusitis for more than 12 weeks.

The old nomenclature changed from calling the disease "sinusitis" to "rhinosinusitis" and is based on the close anatomy and continuous mucosae and the fact that the inflammatory pathophysiology usually affects both the sinuses and the nasal passages. Both organs are lined by pseudostratified columnar epithelium, and both secrete mucus.

The osteomeatal complex plays a vital role in clearing mucus produced in the paranasal sinuses, and damage or inflammation of this complex impairs the normal drainage of sinus mucus. This typically occurs during a viral infection or if ciliary function is impaired. If mucus does not flow normally out of the sinuses, stasis promotes bacterial growth, resulting in inflammation and infection.

Thus in rhinosinusitis, the inflammatory process affects the mucosa of the nose and sinuses and may be associated with mucociliary impairment. ${ }^{4}$ Rhinosinusitis thus has heterogeneous origins, including viruses, bacteria, anatomical abnormalities, polyposis, aspirin sensitivity (Samter's triad), and asthma.

Polyps usually originate in the osteomeatal complex loose connective tissue and are often eosinophilic. Nasal polyps may 
be classified histologically ${ }^{5}$ or endoscopically and clinically ${ }^{6}$ (Table 1). Nasal polyposis is a chronic inflammatory disease and is characterized by markedly increased numbers of eosinophils, Th2-type lymphocytes, fibroblasts, goblet cells, and mast cells. ${ }^{7,8}$ Although some patients may also have concurrent allergic rhinitis, the association between ARS and CRS with allergy has not been clearly defined. ${ }^{7,9}$ Studies have also demonstrated a strong local upregulation of IL-13, thymus and activationregulated chemokine, and $\operatorname{IgE}$ synthesis with the formation of specific IgE to Staphylococcus aureus enterotoxins, suggesting a possible role of superantigens in these pathologic processes. ${ }^{10}$

It is widely believed that most ARS is due to bacterial infection, and in the United States, rhinosinusitis is the fifth most common diagnosis for which antibiotics are prescribed, accounting for 9 and $21 \%$ of all pediatric and adult prescriptions, respectively. ${ }^{1}$ However, bacteria are only present in $60 \%$ of ARS cases, which in most cases resolve spontaneously. ${ }^{11}$ The most common bacterial species isolated include Streptococcus pneumonia, Haemophilus influenzae, Bacteroides fragilis, and Moraxella catarrhalis, the latter being more common in children. ${ }^{10}$ In addition, other conditions such as cystic fibrosis, primary immunodeficiency, acquired immunodeficiency syndrome, cigarette smoking, and hypothyroidism may also predispose to ARS or CRS.

The major symptoms of ARS include nasal blockage, congestion and stuffiness, nasal discharge with postnasal drip, facial pain, pressure, headache, reduction in smell, and purulent mucus. Other symptoms may result from laryngeal and tracheal irritation leading to dysphonia and cough. With systemic involvement and fever, there may be malaise, drowsiness, and complications that may occasionally be serious. ARS is usually treated with antibiotics such as amoxicillin or penicillin for 10 to 14 days, but while antibiotics have been reported to cure $82 \%$ of cases, $69 \%$ of

TABLE 1. Classification of Nasal Polyps

\begin{tabular}{|c|c|}
\hline \multicolumn{2}{|l|}{ Histological } \\
\hline Type 1 & $\begin{array}{l}\text { Eosinophilic edematous } \\
\text { type }\end{array}$ \\
\hline Type 2 & $\begin{array}{l}\text { Chronic inflammatory } \\
\text { or fibrotic type }\end{array}$ \\
\hline Type 3 & Seromucinous gland type \\
\hline Type 4 & Atypical stromal type \\
\hline \multicolumn{2}{|c|}{ Clinical and endoscopical } \\
\hline Type 1 & Antrochoanal polyps \\
\hline Type 2 & Large isolated polyps \\
\hline Type 3 & $\begin{array}{l}\text { Polyps associated with } \\
\text { CRS-noneosinophil } \\
\text { dominated, not related } \\
\text { to hyperreactive } \\
\text { airway syndromes }\end{array}$ \\
\hline Type 4 & $\begin{array}{l}\text { Polyps associated with } \\
\text { CRS-eosinophil } \\
\text { dominated }\end{array}$ \\
\hline Type 5 & $\begin{array}{l}\text { Polyps associated with } \\
\text { specific disease } \\
\text { (eg, cystic fibrosis, } \\
\text { nonallergic sinusitis, } \\
\text { malignancy) }\end{array}$ \\
\hline
\end{tabular}

(C) 2012 World Allergy Organization patients are "cured" with placebo therapy, ${ }^{11,12}$ and there is always the risk of developing antibiotic resistance if they are inappropriately prescribed.

A Cochrane meta-analysis showed a relative risk for cure of 1.78 (95\% confidence interval, 1.00-2.96) for the use of antibiotic therapy, and there were no improved outcomes seen with the newer antibiotics, such as cephalosporins, macrolides, or minocycline compared with penicillins. ${ }^{13}$ In a study by Meltzer et al, ${ }^{14}$ the efficacy and safety of mometasone furoate nasal spray (MFNS) versus amoxicillin and placebo were studied in patients with uncomplicated ARS. Rhinosinusitis may be chronic or may occur recurrently or intermittently.

In this study, 981 subjects older than 12 years were randomized to receive $200 \mu \mathrm{g}$ of mometasone once daily or twice daily for 15 days, $500 \mathrm{mg}$ of amoxicillin 3 times daily for 10 days, or respective placebo. MFNS twice daily was significantly superior to placebo $(P<0.001)$ and amoxicillin $(P \leq 0.001)$ at improving symptom score. Global response to treatment was significantly greater with $200 \mu \mathrm{g}$ of MFNS twice daily versus amoxicillin $(P=0.013)$ and placebo $(P=0.001)$. On the other hand, mometasone once daily was not superior to amoxicillin. ${ }^{14}$ In addition, treatment with amoxicillin did not predispose the patients to recurrent disease. The treatment of uncomplicated ARS with intranasal steroids thus represents a new paradigm in the clinical treatment approaches now available to clinicians in practice.

In view of the fact that the etiology of CRS is poorly understood, the role of bacteria is not well defined, and response to antibiotics is poor, it is necessary to reconsider carefully the pathology of CRS. Immune responses in CRS are complex and varied. Tissue eosinophilia may occur in CRS and shows some relationships to severity, prognosis, and polyp development. Cellular elements in patients with CRS include eosinophils/neutrophils, mast cells, macrophages, lymphocytes and a range of mediators including IL-1, IL-6-IL-8, tumor necrosis factor- $\alpha$, IL-3, granulocyte macrophage colony stimulating factor, intercellular adhesion molecule expression-I, myeloperoxidase and eosinolhilic cationic protein, chemokines (RANTES and eotaxin) and upregulation of leukotriene receptors. $^{1,2,6,7}$ Because the production of many of these inflammatory components is downregulated by steroids, steroid therapy is theoretically an important treatment modality to investigate. The clinical efficacy of glucocorticoids depends in part on their ability to reduce airway eosinophil infiltration and to reduce their viability and activation. ${ }^{15}$

Current indications for corticosteroids in rhinosinusitis recommended by the European Position Paper on Rhinosinusitis (EPOS) guidelines ${ }^{3}$ include the following:

- ARS;

- prophylactic treatment of recurrent ARS;

- CRS without nasal polyps;

- CRS with nasal polyps;

- postoperative treatment of CRS with or without nasal polyps.

There is increasing evidence that for the treatment of CRS without polyps, intranasal steroids are beneficial. Lavigne et $\mathrm{al}^{16}$ investigated the effects of intrasinus 
TABLE 2. Treatment and Grade of Recommendation for Adults With ARS (Adapted From Fokkens et al) ${ }^{3}$

\begin{tabular}{lll}
\hline Therapy & Grade of Recommendation & Relevance \\
\hline Oral antibiotic & A & After $5 \mathrm{~d}$ or severe cases \\
Topical corticosteroid & A & Evidence based \\
Topical corticosteroid plus oral antibiotic & A & Evidence based \\
Oral corticosteroid & A & For pain reduction in severe disease \\
Oral antihistamine & B & Only in allergic patients \\
Decongestants & D & As symptomatic relief \\
Mucolytics, douche phytotherapy & D & No role \\
\hline
\end{tabular}

instillation of budesonide in patients with CRS who were also allergic and documented a regression of more than $50 \%$ of total nasal symptom scores over a 3 -week period with a concomitant reduction in $\mathrm{CD} 3^{+} \mathrm{T}$ cells, eosinophils, and cells expressing IL-4 and IL-5.

These findings were confirmed in a later study by Lund et $\mathrm{al}^{17}$ in a double-blind, placebo-controlled, randomized trial of 134 patients with CRS without nasal polyps treated with topical intranasal budesonide for 20 weeks. In this study, both symptom score and peak inspiratory nasal flow were improved.

There is, however, no data showing efficacy of oral corticosteroids in CRS without nasal polyps. However, the addition of $400 \mu \mathrm{g}$ of MFNS twice daily to antibiotics results in a significantly greater decrease in total symptom score and individual scores of inflammatory symptoms associated with obstruction (headache, congestion, and facial pain) compared with placebo in patients with recurrent rhinosinusitis in a study published by Meltzer et al. ${ }^{18}$. For patients with CRS with nasal polyps, there have been numerous studies on the use of intranasal and oral steroids. ${ }^{19-23}$

In a study by Holmberg et al, ${ }^{22} 400 \mu \mathrm{g}$ of fluticasone propionate and $200 \mu \mathrm{g}$ of beclomethasone dipropionate (BDP) were compared with placebo over a 26 -week period in a double-blind parallel group in patients with bilateral nasal polyps. There was a significant improvement in symptoms and peak nasal inspiratory flow for both steroid groups when compared with placebo, with no statistical differences between the 2 active groups, unrelated to the grade of polyps.

In a study by Keith et $\mathrm{al}^{23}$ using the same dose of fluticasone dipropionate compared with placebo for 12 weeks, in 52 patients, polyp reduction was not significant, but nasal blockage and peak inspiratory flow were significantly improved in the group treated with intranasal steroids, and other than a few cases of epistaxis, no other side effects were reported.

If one considers all the published studies summarized in the EPOS guidelines on the treatment of CRS without polyps with corticosteroids, ${ }^{16,17,24-26} 4$ of the 5 studies showed significant improvements, with improvements in maxillary ostial potency, ${ }^{25}$ mucociliary clearance, ${ }^{26}$ airway peak nasal inspiratory flow, ${ }^{17}$ and effects on $\mathrm{T}$ cells, eosinophils, and messenger RNA for IL-4 and IL-5. ${ }^{16}$ Thus, the overall conclusion is that steroids given intranasally are of benefit to patients with CRS without polyps and those with polyps.

Side effects of topical corticosteroids in nasal polyps are rare. Minor nose bleeding has been reported in some subjects and is attributed to the vasoconstrictor activity of corticosteroids. Septal perforation is extremely rare. ${ }^{27}$ Nasal biopsy studies have not shown any detrimental structural effects within the nasal mucosa with long-term administration of intranasal corticosteroids. ${ }^{28}$

The systemic bioavailability of intranasal steroids is variable, and depending on the steroid, potential side effects include effects on growth, ocular effects, and effects on the bone and the hypothalamic pituitary adrenal axis. Thus, steroids such as mometasone furoate and fluticasone furoate, which have however systemic bioavailability, would be considered safer, particularly if higher doses are used than the doses of intranasal steroids used for treating uncomplicated allergic rhinitis.

\section{SUMMARY}

Rhinosinusitis is a significant health problem, but published data on CRS are limited, and the disease entity is still poorly defined, ranging from an expression of the disease

TABLE 3. Treatment and Grade of Recommendation for Adults With CRS With Nasal Polyps (Adapted From Fokkens et al) ${ }^{3}$

\begin{tabular}{|c|c|c|}
\hline Therapy & Grade of Recommendation & Relevance \\
\hline Short-term oral antibiotics $<2 \mathrm{wk}$ & $\mathrm{D}$ & No data \\
\hline Oral antibiotics $>12 \mathrm{wk}$ & $\mathrm{D}$ & No data (possibly for relapse) \\
\hline Topical antibiotic & $\mathrm{D}$ & No data \\
\hline Topical steroids & A & Evidence based \\
\hline Oral steroids & A & Evidence based \\
\hline Decongestant & $\mathrm{D}$ & No data in single use \\
\hline $\begin{array}{l}\text { Mucolytics, antimycotics, immune modulations, } \\
\text { phytotherapy }\end{array}$ & $\mathrm{D}$ & No data \\
\hline Oral antihistamine & $\mathrm{A}$ & In allergic patients \\
\hline Antileukotrienes & $\mathrm{C}$ & Minimal data \\
\hline
\end{tabular}


as discrete acute episodes, which are well defined, to several different clinical and histological forms of a CRS, in many of which nasal and sinus polyposis is a significant component. A summary of the EPOS guidelines for the role of different treatments for ARS and CRS is given in Tables 2 and $3 .^{29}$

It is clear from the different pathophysiological findings of different polyps that the disease is multifunctional and no single factor can explain the pathogenesis of polyps in CRS; however, chronic persistent inflammation is undoubtedly a major factor, irrespective of the etiology. ${ }^{30}$

Further studies are important to address the optimal therapy, particularly for recurrent and resistant cases.

\section{ACKNOWLEDGMENTS}

The contents of this article were presented as an invited World Allergy Organization Lecture at the First Middle East Asia Allergy Asthma and Immunology Congress (MEAAAIC) in Dubai, UAE, March 26-29, 2009, as part of the symposium, "Current Concepts in Allergic Rhinitis, Rhinosinusitis and New Developments in Histamine-mediated Diseases."

Schering-Plough provided an educational grant for the symposium.

\section{REFERENCES}

1. Thomas M, Yawn B, Price D, Lund V, Mullol J, Fokkens W; on behalf of the European Position Paper on Rhinosinusitis and Nasal Polyps Group. EPOS primary care guidelines: European position paper on the primary care diagnosis and management of rhinosinusitis and nasal polyps 2007 - a summary. Prim Care Respir J. 2008;17:79-89.

2. Lim M, Lew Gor S, Darby Y. The relationship between subjective assessment instruments in chronic rhinosinusitis. Rhinology. 2007;45:144-147.

3. Fokkens W, Lund V, Mullol J; on behalf of the European Position Paper on Rhinosinusitis and Nasal Polyps Group. Rhinology. 2007; (suppl 20):1-136.

4. Sturgens JM, Chao J, Wong J, Aspin N, Turner NA. Cilia with defective radial spokes: a cause of human respiratory disease. $N$ Engl J Med. 1979;300:53-56.

5. Hellquist HB. Nasal polyps update: histopathology. Allergy Asthma Proc. 1996;17:237-242.

6. Stammberger H. Examination and endoscopy of the nose and paranasal sinuses. In: Miggind N, Lildholdt T, eds. Nasal Polyposis: An Inflammatory Disease and Its Treatment. Copenhagen, Denmark: Munksgaard; 1997:120-136.

7. Hamilos DL, Leung DY, Wood R, Cunningham L, Bean DK, et al. Evidence for distinct cytokine expression in allergic versus nonallergic chronic sinusitis. J Allergy Clin Immunol. 1995;96:537-544.

8. Pawankar R. Nasal polyposis: an update: editorial review. Curr Opin Allergy Clin Immunol. 2003;3:1-6.

9. Kartsson G, Holmberg K. Does allergic rhinitis predispose to sinusitis. Acta Otolaryngol Suppl. 1994;515:26-28.

10. Van Zele T, Gevaert P, Watelet JB, Claeys G, Holtappels G, et al. Staphylococcus aureus colonization and IgE antibody formation to enterotoxins is increased in nasal polyposis. J Allergy Clin Immunol. 2004;114:981-983.
11. Leggett J. Acute sinusitis: when and when not to prescribe antibiotics. Postgrad Med. 2004;115:13-19.

12. Gwaltney JM. Acute community acquired sinusitis. Clin Infect Dis. 1996;23:1209-1223.

13. Williams JW, Agullar C, Cornel J. Antibiotics for acute maxillary sinusitis. Cochrane Database Syst Rev. 2003.

14. Meltzer EO, Bachert C, Staudinger H. Treating acute rhinosinusitis: comparing efficacy and safety of mometasone furoate nasal spray, amoxicillin and placebo. J Allergy Clin Immunol. 2005;116:1289-1295.

15. Mullol J, Xanbet A, Lopez E, Roca-Ferrer J, Picado C. Comparative study of the effects of different corticosteroids on eosinophil survival primed by cultivated epithelial cell supernatants obtained from nasal mucosa and polyps. Thorax. 1995;50:270-274.

16. Lavigne F, Cameron L, Renzi PM, Planef JF, Christo Doulopoulos P, Lamkiched B. Intrasinus administration of topical budesonide to allergic patients with chronic rhinosinusitis following surgery. Laryngoscope. 2002;12:858-864

17. Lund V, Black JH, Szabo LZ, Schreweling C, Akerlund A. Efficacy and tolerability of budesonide aqueous nasal spray in chronic rhinosinusitis patients. Rhinology. 2004;42:57-62.

18. Meltzer EO, Charous L, Busse W, Zinreich J, Lorber R, Danzig M. Added relief in the treatment of acute recurrent sinusitis with adjunctive mometasone furoate nasal spray. J Allergy Clin Immunol. 2000;106:630-637.

19. Deuschl H, Drettner B. Nasal polyps treated by betamethazone nasal aerosol. Rhinology. 1977;15:17-23.

20. Van Camp C, Clement PA. Results of oral steroid treatment in nasal polyposis. Rhinology. 1994;32:5-9.

21. Drettner B, Ebbesen A, Nilsson M. Prophylactic treatment with flunisolide after polypectomy. Rhinology. 1982;20:149-158.

22. Holmberg K, Juliusson S, Balder B, Smith D, Richards DH, Karlsson G. Fluticasone propionate aqueous spray in the treatment of nasal polyposis. Ann Allergy Asthma Immunol. 1997;78:270-276.

23. Keith P, Nieminen J, Hollingworth K, Dolovich J. Efficacy and tolerability of fluticasone propionate nasal drops $400 \mathrm{mcg}$ once daily compared with placebo for the treatment of bilateral polyposis in adults. Clin Exp Allergy. 2000;30:1460-1468.

24. Parikh A, Scadding GK, Darby Y, Barker RC. Topical corticosteroids in chronic rhinosinusitis: a randomised double blind placebo controlled trial using fluticasone propionate aqueous nasal spray. Rhinology. 2001;39: 75-79.

25. Cuenant G, Stipon JP, Plante-Longchamp G, Bandon C. Effects of endonasal tixocortol pivalate irrigation in the treatment of chronic allergic and bacterial sinusitis. J Otorhinolaryngol Relat Spec. 1986;48:226-232.

26. Sykes DA, Wilson R, Chan KL, Mackay IS, Cole PJ. Relative importance of antibiotic and improved clearance in topical treatment of chronic mucopurulent rhinosinusitis: a controlled study. Lancet. 1986;16: 359-360.

27. Salib RJ, Flowarth PH. Safety and tolerability profiles of intranasal antihistamines and intranasal corticosteroids in the treatment of allergic rhinitis. Drug Saf. 2003;26:863-893.

28. Hom AF, Fokkens WJ, Godthelp T, Mulder PG, Vroom TM, Rinjtes E. A 1 year placebo controlled study of intranasal fluticasone propionate aqueous nasal spray in patients with perennial allergic rhinitis: a safety and biopsy study. Clin Otolaryngol. 1998;23:69-73.

29. Fokkens W, Lund V, Mullol J; on behalf of the European Position Paper on Rhinosinusitis and Nasal Polyps Group. EP3OS 2007: European position paper on rhinosinusitis and nasal polyps 2007: a summary for otorhinolaryngologists. Rhinology. 2007;45:97-101.

30. Kirtreesakul V. Update on nasal polyposis: etiopathogenesis. $J$ Med Assoc Thai. 2005;88:1966-1972. 